\title{
Design of a New Soil-Tuber Separation Device on Potato Harvesters
}

\author{
Gaili Gao*, Dongxing Zhang, and Jun Liu \\ College of Engineering, China Agricultural University, Beijing 100083, P.R. China \\ ggl1965@126.com, ggl@cau.edu.cn
}

\begin{abstract}
A new soil-tuber separation device on potato harvesters has been developed. It mainly comprises a linear motor, a rectangular screen, a frame, four supporting springs and four dampers. It is the first time to propose that the soil-tuber separation device is driven by the linear motor. Forces acting on the rectangular screen are found. A differential equation for describing the forces is set up. An equation for evaluating exciting force of the linear motor has been derived from the solution to the differential equation. An equation of the factors affecting on the device resonance has also been obtained. Additionally, an equation for evaluating the deformed magnitude of the damping springs in the dampers has been derived. And finally a motion simulation experiment for the rectangular screen on a potato harvester has been done with the Matlab/Simulink module. The experiment expressed that the method is feasible.
\end{abstract}

Keywords: Potato harvester, Soil-tuber separation, Separation device, dynamics analysis.

\section{Introduction}

Many methods were used to separate soil from potatoes. However, field separating operation caused most damage to potatoes. Curl (1978) invented a tuber harvester having a primary bed and a secondary bed. The secondary bed is encompassed by a devining chain [1]. Hyde et al. (1983) suggested this type of tuber harvester could be equipped with a system for controlling the depth of material on the primary chain by automatically adjusting chain speed. The system provides uniform flow of material from the primary to the secondary chain over a wide variety of field conditions and ground speeds [2]. Another similar potato harvester was described by Welp (1989). It comprises a screening conveyor belt and an elevator disposed after the screening conveyor belt. The elevator is formed from a double conveyor having an internally rotating bar-type conveyor belt with narrow openings and an externally rotating bar-type conveyor belt with wide openings [3]. In order to improve soil elimination, shaking of the conveyor chain (bed) in a vertical or horizontal direction was applied to

\footnotetext{
* Corresponding author.
} 
the potato harvesters (Woodruff et al., 1984) [4]. In addition, a pressure belt mechanism operating on the surface of the primary conveyor was proposed (Misener et al., 1989) [5]. However, due to friction between chain (bed) or soil and potatoes, the potatoes were greatly damaged. A simple mechanical separator was developed by Feller et al.(1985) . The machine utilizes the difference in the restitution coefficient between potatoes and soil clods.Both potatoes and clods are dropped from a feed conveyor onto a revolving steel roller where the resulting trajectories cause the potatoes to end up at a more remote location than the clods. The separator can not be used to separate stones from the potatoes [6]. Gan-Mor et al.(1986) used a appropriate elastic plate for reducing the restitution coefficient of stones without changing that of the potatoes or clods so that the stones were separated [7]. However, the impact between the steel roller or plate and potatoes caused damage to potatoes. Bouillon (1983) proposed another potato harvesting apparatus. Its separator has three primary cylindrical cages, followed by three secondary cylindrical cages and then three rubber-coated cylindrical cages. The separator can remove most of the dirt and break up the dirt clods [8]. However, much of mechanical injury was caused by the conveyor equipment. In addition, great power required to drive the separator was consumed. Misener and McLeod (1989) also tested a mechanism which consists of a combination of disc-shaped clod rollers and cylindrical brushes. The mechanism essentially eliminated the loose soil and, on the average, $60 \%$ of the stones and $47 \%$ of the clods [9].

The objective of this research is to develop a new soil-tuber separation device on potato harvesters. The device can reduce potato damage, reduce the power required to separate soil from potatoes, and improve the separation efficiency.

Specific work is divided into three parts:

(1) Model of soil-tuber separation device.

(2) Dynamics analysis for soil-tuber separation device.

(3) A motion simulation experiment for a rectangular screen.

\section{Model of Soil-Tuber Separation Device}

A model of a soil-tuber separation device on a potato harvester is shown in Fig. 1. The device mainly comprises a linear motor, a rectangular screen, a frame, four supporting springs (two of the supporting springs aren't shown in Fig. 1), and four dampers. The rectangular screen consists of equidistantly spaced bars at the center and a connecting plate on each side of the bars. The frame has four inside slideways and two bottom supporting plates. The motionless part of the linear motor is held onto the frame by connecting components (the connecting components aren't shown in Fig. 1). The motion part of the linear motor is attached to the connecting plates of the rectangular screen by another connecting components (the connecting components aren't shown in Fig. 1). The rectangular screen is connected to the supporting plates of the frame by the four supporting springs. The frame is equipped with the four dampers each of which has a spring, a guide, and a spring cover (the spring cover isn't shown in Fig. 1). 
The angle between the datum plane of the device and the level is $\beta$. When the device works the rectangular screen driven by the motion part of the linear motor vibrates up and down in inclined direction along the four slideways of the frame and the four guides of the dampers.

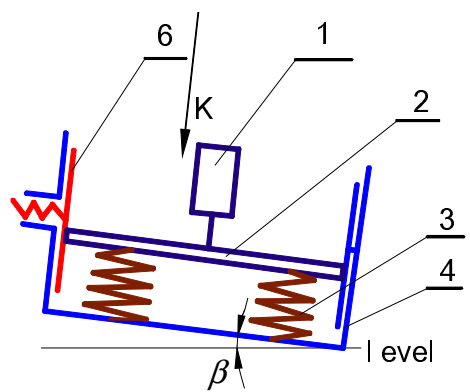

(a)

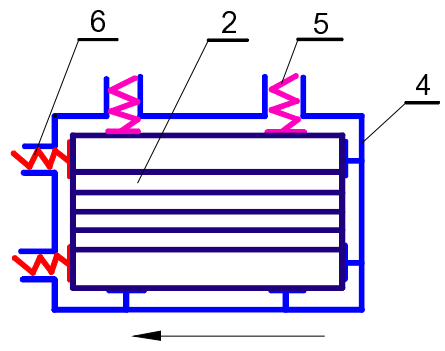

(b)

Fig. 1. A model of a soil-tuber separation device: (a) front view; (b) K direction view except the linear motor .1-linear motor; 2-rectangular screen; 3- supporting springs; 4-frame; 5-dampers; 6 -dampers. Arrow denotes direction of travel.

\section{Dynamics Analysis for Soil-Tuber Separation Device}

\subsection{Evaluation of Exciting Force}

The forces exerted on the rectangular screen in vibrating direction are (Fig. 2): exciting force of the linear motor acting on the top of the rectangular screen, $F$; supporting force of the supporting springs acting on the bottom of the rectangular screen, $N$; damping due to surface friction from the motion of the rectangular screen, $F^{\prime}$; and component of gravitational force of the rectangular screen that includes the tuber and soil on it, $m g \cos \beta$.

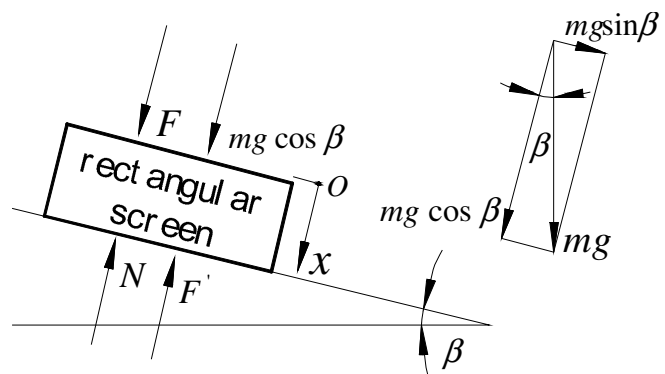

Fig. 2. Forces acting on a rectangular screen in vibrating direction 
Using vibrating direction as $x$ axis and putting the stagnation point $O$ at equilibrium position (Fig. 2), the supporting force in the $x$ direction may be described as follows:

$$
N=i K\left(x+\lambda_{s}\right) \text {. }
$$

Where $i$ is number of the supporting springs, $K$ is stiffness of the supporting springs ( $N m^{-1}$ ), $\lambda_{s}$ is the deformed magnitude of the supporting springs at equilibrium position $(m), x$ is the distance of the rectangular screen from the equilibrium position $(m)$.

The exciting force is defined by:

$$
F=F_{0} \sin \omega t
$$

Where $F_{0}$ is amplitude of the exciting force $(N), \omega$ is angular frequency of the exciting force ( $\mathrm{rad} s^{-1}$ ), $t$ is the exciting time $(s)$.

The damping may be expressed as follows [10]:

$$
F^{\prime}=\gamma_{e} \dot{x}
$$

Where $\gamma_{e}$ is damping coefficient $\left(N s m^{-1}\right)$.

Based on Newton's law of motion the differential equation for describing the forces acting on the rectangular screen is:

$$
F+m g \cos \beta-N-F^{\prime}=m \ddot{x} .
$$

Where $m$ is mass ( $k g), g$ is acceleration of gravity $\left(m s^{-2}\right), \beta$ is the angle between the datum plane of the device and the level ( deg .).

$$
\text { At equilibrium position } \quad m g \cos \beta=i K \lambda_{s} \text {. }
$$

Substituting equation (1),(2),(3),and(5) into equation (4) and rearranging terms gives:

$$
m \ddot{x}+\gamma_{e} \dot{x}+i K x=F_{0} \sin \omega t
$$

If we define $2 n=\frac{\gamma_{e}}{m}, \quad p^{2}=\frac{i K}{m} \quad$ and $\quad q=\frac{F_{0}}{m}$

then equation (6) becomes:

$$
\ddot{x}+2 n \dot{x}+p^{2} x=q \sin \omega t .
$$

A particular solution to equation (7) is:

$$
x(t)=B \sin (\omega t-\psi) .
$$

where

$$
B=\frac{q}{\sqrt{\left(p^{2}-\omega^{2}\right)^{2}+4 n^{2} \omega^{2}}} .
$$


and

$$
\operatorname{tg} \psi=\frac{2 n \omega}{p^{2}-\omega^{2}}
$$

Rearranging equation (9) yields:

$$
B=\frac{q}{p^{2}} \cdot \frac{1}{\left.\sqrt{\left[1-\left(\frac{\omega}{p}\right)^{2}\right]^{2}+\left[2 \frac{n}{p}\right.} \frac{\omega}{p}\right]^{2}} .
$$

If we define $B_{0}=\frac{q}{p^{2}}=\frac{F_{0}}{i K}, \lambda=\frac{\omega}{p}$ and $\zeta=\frac{n}{p}$

then equation (11) becomes:

$$
\begin{aligned}
& B=\frac{B_{0}}{\sqrt{\left(1-\lambda^{2}\right)^{2}+(2 \zeta \lambda)^{2}}} . \\
& F_{0}=i K B \sqrt{\left(1-\lambda^{2}\right)^{2}+(2 \zeta \lambda)^{2}} .
\end{aligned}
$$

or

If we define $\theta=\frac{B}{B_{0}}$

then equation (12) becomes:

$$
\theta=\frac{1}{\sqrt{\left(1-\lambda^{2}\right)^{2}+(2 \zeta \lambda)^{2}}}
$$

Differentiating equation (14) with respect to $\lambda$ and setting the derivative equal to zero, we obtain:

$$
\begin{array}{rlrl}
\lambda & =\sqrt{1-2 \zeta^{2}} . \\
& \text { or } \quad & =\sqrt{p^{2}-2 n^{2}} . \\
\because & 2 n^{2}<<p^{2} . \\
\therefore & \omega & =\sqrt{\frac{i K}{m} .}
\end{array}
$$

Equation (16) is the requirement of occurring resonance for the device. 
Based on damping theory the damping coefficient is [10]:

$$
\gamma_{e}=\frac{4 F^{\prime}}{\pi \omega B} .
$$

Substituting equation (17) into $2 n=\frac{\gamma_{e}}{m}, \quad p^{2}=\frac{i K}{m} \quad$ and $\quad \zeta=\frac{n}{p}$, rearranging terms gives:

$$
\zeta=\frac{2 F^{\prime}}{\pi \omega B \sqrt{i K m}}
$$

Substituting equation (15)and(18) into equation (13) yields:

$$
F_{0}=\frac{4 F^{\prime}}{(\pi \omega)^{2} m B} \sqrt{(\pi \omega B)^{2} i K m-4 F^{\prime 2}} .
$$

Equation (19) is used to evaluate the amplitude of the exciting force. Equation (2), (16) and (19) is applied to evaluate the magnitude of the exciting force.

\subsection{Analysis of Damping}

The forces exerted on the rectangular screen at the plane perpendicular to the vibrating direction are (Fig. 3): composite pressure force of the two 5-dampers, $N_{1}$; composite pressure force of the two 6-dampers, $N_{2}$; reacting forces of the frame, $N_{1}^{\prime}$ and $N_{2}^{\prime}$; and component of gravitational force of the rectangular screen that includes the tuber and soil on it, $m g \sin \beta$.

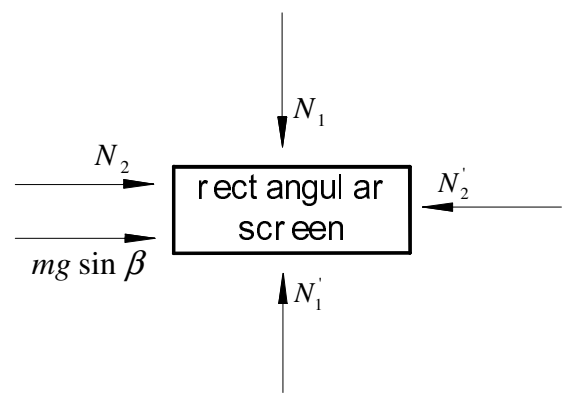

Fig. 3. Forces acting on a rectangular screen at the plane perpendicular to the vibrating direction 
The composite pressure force of the two 5-dampers is determined as:

$$
N_{1}=2 k_{1} x_{1} \text {. }
$$

Where $k_{1}$ is stiffness of the spring in the 5-damper $\left(N m^{-1}\right), x_{1}$ is the deformed magnitude of the spring in the 5-damper $(m)$.

The composite pressure force of the two 6-dampers is determined as:

$$
N_{2}=2 k_{2} x_{2} \text {. }
$$

Where $k_{2}$ is stiffness of the spring in the 6-damper $\left(N m^{-1}\right), x_{2}$ is the deformed magnitude of the spring in the 6-damper $(m)$.

The reacting forces may be expressed as:

$$
\begin{gathered}
N_{1}^{\prime}=2 k_{1} x_{1} . \\
N_{2}^{\prime}=N_{2}+m g \sin \beta .
\end{gathered}
$$

The damping may also be evaluated by:

$$
F^{\prime}=\mu N_{1}+\mu N_{1}^{\prime}+\mu N_{2}+\mu N_{2}^{\prime} .
$$

Where $\mu$ is friction coefficient between the 5-damper or the 6-damper and the rectangular screen. It is also the friction coefficient between the slideways of the frame and the rectangular screen .

Substituting equation (20),(21),(22), and(23) into equation (24) and rearranging terms gives:

$$
F^{\prime}=4 \mu\left(k_{1} x_{1}+k_{2} x_{2}\right)+\mu m g \sin \beta .
$$

From equations (25)

$$
k_{1} x_{1}+k_{2} x_{2}=\frac{F^{\prime}-\mu m g \sin \beta}{4 \mu} .
$$

Equation (26) is applied to evaluate the deformed magnitude of the damping springs in the four dampers.

\section{Results and Discussion}

A motion simulation experiment for the rectangular screen on a potato harvester has been done with the Matlab/Simulink module. The parameters of the experiment are:

(1) $i=4, m=300 \mathrm{~kg}, B=0.05 \mathrm{~m}, \omega=\pi \mathrm{rad} / \mathrm{s}, F^{\prime}=80 \mathrm{~N}$.

(2) $i=4, m=500 \mathrm{~kg}, B=0.05 \mathrm{~m}, \omega=\pi \mathrm{rad} / \mathrm{s}, F^{\prime}=80 \mathrm{~N}$.

(3) $i=4, m=800 \mathrm{~kg}, B=0.05 \mathrm{~m}, \omega=\pi \mathrm{rad} / \mathrm{s}, F^{\prime}=80 \mathrm{~N}$. 
The exciting force $F$ was calculated in equation (2), (16) and (19). The simulation result was as shown in Fig.4. We could see that the motion trail of the rectangular screen is correct.

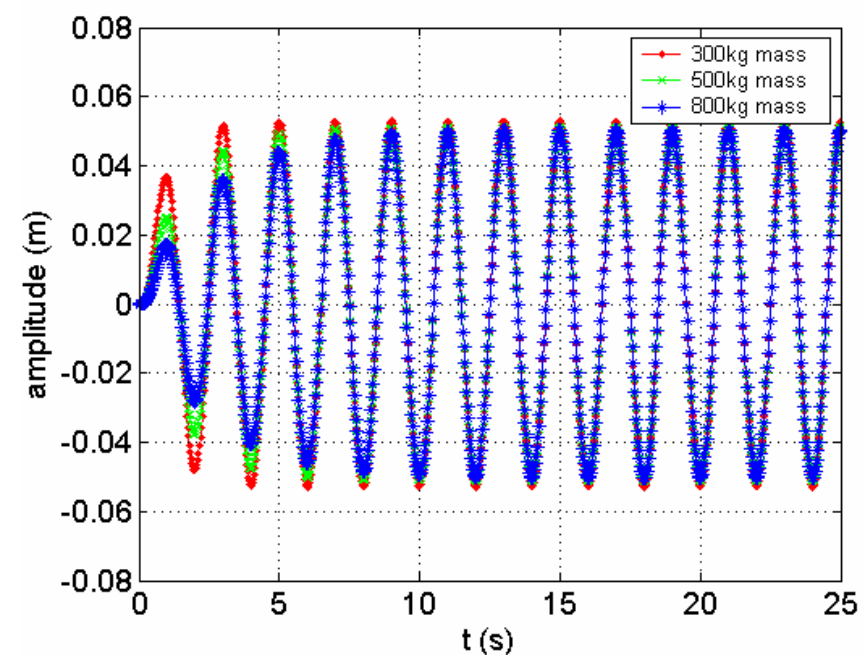

Fig. 4. Displacement-time curve for the rectangular screen on a potato harvester

In practice, the stiffness $k_{1}, k_{2}$ and the deformed magnitude $x_{1}, x_{2}$ of the springs in the dampers could be adjusted. Therefore the appropriate damping $F^{\prime}$ could be obtained in equation (25). The motion simulation experiment expressed that the method is feasible.

\section{Conclusions}

(1) A new soil-tuber separation device on potato harvesters has been developed. It is the first time to propose that the soil-tuber separation device is driven by the linear motor.

(2) Forces acting on the rectangular screen are found. A differential equation for describing the forces is set up. An equation for evaluating exciting force of the linear motor has been derived from the solution to the differential equation. An equation of the factors affecting on the device resonance has also been obtained. Additionally, an equation for evaluating the deformed magnitude of the damping springs in the dampers has been derived.

(3) A motion simulation experiment for the rectangular screen on a potato harvester has been done with the Matlab/Simulink module. The experiment expressed that the method is feasible. 


\section{References}

1. Curl, R .B.: Potato harvester. U.S.Patent, No.4121667 (1978)

2. Hyde, G.M., Thornton, R.E., Woodruff, D.W.: Potato harvester performance with automatic chain-load control. Transactions of the ASAE 26, 19-22 (1983)

3. Welp, J.: Potato harvester. U.S.Patent, No.4842076 (1989)

4. Woodruff, D.W., Hyde, G.M., Thornton, R.E.: A preliminary analysis of a high-frequency soil riddling device for use on potato harvesters. Transactions of the ASAE 27, 1638-1642 (1984)

5. Misener, G.C., McLeod, C.D., McMillan, L.P.: Improved design for soil separation and vine removal mechanisms on a potato harvester. Appl. Eng. Agric. 5, 522-526 (1989)

6. Feller, R., Margolin, E., Zacharin, A., Pasternak, H.: Development of a clod separator for potato packing houses. Transactions of the ASAE 28, 1019-1023 (1985)

7. Gan-Mor, S., Zacharin, A., Gaili, N., Feller, R., Margolin, E.: Absorbing stone impact to enable separation from potatoes. Transactions of the ASAE 29, 1526-1529 (1986)

8. Bouillon, A.M.: Potato harvesting apparatus. U.S.Patent, No.4416334 (1983)

9. Misener, G.C., McLeod, C.D.: A resource efficient approach to potato-stone-clod separation. AMA Agric. Mech. Asia Afr. Lat. Am. 20, 33-36 (1989)

10. Zhang, Y.: Mechanical Vibration. Tsinghua University Press, Beijing (2007) 